\title{
Co-infection of Beet mosaic virus with Beet Yellowing Viruses Leads to Increased Symptom Expression on Sugar Beet
}

\author{
William M. Wintermantel, United States Department of Agriculture, Agricultural Research Service, 1636 E. Alisal \\ Street, Salinas, CA 93905
}

\begin{abstract}
Wintermantel, W. M. 2005. Co-infection of Beet mosaic virus with beet yellowing viruses leads to increased symptom expression on sugar beet. Plant Dis. 89:325-331.

Three distinct aphid-transmitted viruses associated with a yellowing disease on sugar beet were examined in single and mixed infections for the effects of virus interactions on plant weight, rate of symptom development, and virus concentration. Sugar beet lines exhibiting different degrees of susceptibility to the virus yellows complex were inoculated with either one, two, or all three viruses. Severe stunting, as measured by fresh plant biomass, was observed with mixed infections with Beet yellows virus (BYV) and Beet mosaic virus (BtMV), compared to single infections of these viruses. In addition, the overall rate of appearance of Beet western yellows virus (BWYV) symptoms increased during co-infection with BtMV. Synergistic effects on stunting severity, as measured by plant biomass, were more pronounced in susceptible beet lines, but similar patterns also were observed in lines exhibiting tolerance to virus yellows. Relative concentrations of viruses were compared among single and mixed infections using dot-blot hybridization with virus specific probes, and quantified by phosphorimage analysis. Titers of all three viruses increased as a result of co-infection compared with single infections.
\end{abstract}

Additional keywords: closterovirus, polerovirus, potyvirus, resistance, synergism

"Virus yellows" is a term frequently used by the sugar beet industry, and refers to a disease resulting from a complex of viruses causing beet leaves to yellow prematurely. Virus yellows has contributed to disease-related yield losses in California sugar beet production for many years (7). Different individual viruses or virus combinations are responsible for the disease in the many sugar beet production regions of the world. Beet yellows virus (BYV; family Closteroviridae, genus Closterovirus), Beet western yellows virus (BWYV; family Luteoviridae, genus Polerovirus), and Beet chlorosis virus (BChV; family Luteoviridae, genus Polerovirus) contribute to the disease in the United States (Table 1) $(13,14,20)$. In Europe, Beet mild yellowing virus (BMYV; family Luteoviridae, genus Polerovirus) is the predominant virus associated with the disease (Table 1), although the other three are also present in some areas $(13,14,20)$. It is not uncommon for multiple aphid-transmitted viruses to infect the same plant simultaneously. All viruses associated with the virus yellows complex

Corresponding author: W. M. Wintermantel E-mail: wwintermantel@pw.ars.usda.gov

Accepted for publication 1 November 2004.

DOI: 10.1094/PD-89-0325

This article is in the public domain and not copyrightable. It may be freely reprinted with customary crediting of the source. The American Phytopathological Society, 2005. are transmitted by the green peach aphid (Myzus persicae Sulzer) (Table 1). Other aphids, such as Aphis fabae Scopoli (a highly efficient vector of BYV), can transmit some members of the complex; but $M$. persicae is the only vector known to efficiently transmit all yellowing viruses of sugar beet (13).

Symptoms on sugar beet resulting from BYV infection begin with light veinclearing visible on leaves early in infection, followed later by development of interveinal yellowing on subsequent leaves (Table 1). Infection by BWYV produces an interveinal yellowing symptom difficult to distinguish from that caused by BYV. In contrast to BYV, however, infection by BWYV or other beet-infecting poleroviruses does not produce the initial veinclearing symptom (Table 1). A third type of virus associated with virus yellows is Beet mosaic virus (BtMV; family Potyviridae, genus Potyvirus; Table 1). BtMV is present in all beet-growing regions throughout the world $(25,27)$ and is often found in fields with virus yellows (13), although it is not considered a yellowing virus. Infection of sugar beet by BtMV results in a generalized leaf mottling or mosaic (Table 1), but only a slight decrease in overall plant growth. In areas where virus yellows is widespread, sugar yield can be decreased by as much as $50 \%$ as a result of early infection. This effect is primarily attributed to BYV, although other yellowing viruses can impact sugar yield as well if infection occurs early
$(5,13,32)$. Seed yields may be decreased by up to $70 \%$ as a result of virus yellows infection (6). Each virus in the yellows complex differs in its effect on yield in single infections. BYV infection results in decreased leaf area and losses in both root weight and sugar yield (13). Yield losses associated with BWYV infection are much less than those resulting from infection by BYV (13). BtMV infections result in less than $10 \%$ yield loss even when plants are infected early (13).

Members of all three virus genera (represented here by BYV, BWYV, and BtMV) can be present in plants at the same time. Although BtMV is widespread in sugar beet production worldwide, it was not clear what effect interactions between BtMV and yellowing viruses could have on disease development. Furthermore, no studies had been conducted on the effects of mixed infections of these viruses on the rate of disease development or on virus concentration in sugar beet plants. Possible effects of mixed infections were suggested by field studies demonstrating that yield and sugar content reductions were more severe during field infection with combinations of these viruses (30). Studies by Shepherd et al. (30) indicated additive effects on yield (tons/acre), and in some cases sugar content, during co-infection by BYV, BWYV, or BtMV. In addition, studies on other virus synergisms have identified interactions between potyviruses and members of both the Closteroviridae $(11,16)$ and Luteoviridae $(3,4)$. Studies conducted in the 1980s with a close relative of BWYV, Potato leafroll virus (PLRV; family Luteoviridae, genus Polerovirus), found that PLRV accumulation increased dramatically, and the ability of PLRV to exit phloem was enhanced, during co-infection of Nicotiana clevelandii and $N$. benthamiana with potyviruses $(3,4)$. The leader-proteinase (L-Pro) encoded by the closterovirus, BYV, interferes with accumulation and systemic movement of another potyvirus, Tobacco etch virus, in a host-specific manner (11), suggesting the possibility of interactions between BtMV and BYV as well. Sweet potato chlorotic dwarf disease is the result of a virus disease complex involving interactions between a potyvirus and a crinivirus (family Closteroviridae) (16). In this synergism, concentrations of the potyvirus, Sweet potato feathery mottle virus (SPFMV), were markedly elevated as a 
result of co-infection by the crinivirus, Sweet potato chlorotic stunt virus (SPCSV). Interestingly, both synergisms involving a potyvirus and a member of the Closteroviridae contrast with the traditional view of potyvirus synergisms, in which the potyvirus remains unaffected but facilitates accumulation of the associated virus (34).

The purpose of the experiments described herein was to determine the effect of infection by multiple viruses associated with virus yellows of sugar beet on symptom expression and plant growth. Three viruses associated with virus yellows (BYV, BWYV, and BtMV) were introduced into sugar beet breeding lines varying in susceptibility to virus yellows, in order to examine virus interactions that affect the rate of symptom development, fresh plant biomass, and virus nucleic acid concentration in leaf tissue.

\section{MATERIALS AND METHODS}

Plant varieties and aphid transmissions. Two susceptible sugar beet breeding lines and two lines with tolerance to virus yellows $(18,19)$ were selected for these studies (Table 2) based on their documented performance in field trials for control of virus yellows $(18,19)$. The susceptible lines, SP22-0 and US75, allow efficient virus accumulation and develop the full range of symptoms associated with infection by yellowing viruses. Although no sources of true resistance to virus yellows have been identified to date, the tolerant lines, C37 and C76-89-5, both perform well in the field under heavy disease pressure, including during mixed infections $(18,19)$. C37 and C76-89-5 allow BYV and BWYV to accumulate and produce foliar symptoms, but do not exhibit the stunting and decreased sugar yield found in susceptible lines under virus yellows disease pressure.

All four sugar beet lines were challenged by aphid-inoculation of BYV, BWYV, and/or BtMV, individually, as mixed pairs, or with all three viruses together. Mock inoculations also were performed with virus-free aphids. Green peach aphids (Myzus persicae Sulzer; hereafter referred to as GPA) were reared on healthy Daikon radish (Raphanus sativus L.) in isolation cages in the green- house. The virus isolates BYV-OR and BWYV-OR were obtained from sugar beet steckling nurseries near Medford, OR. BtMV-WA was obtained from table beet collected in the state of Washington. All three isolates have been maintained by the Salinas Virology Lab for several years. These isolates were increased on source plants prior to transmission to provide inoculum for aphid feeding. BYV was increased on New Zealand Spinach (Tetragonia expansa Murr.), BWYV on shepherd's purse (Capsella bursa-pastoris L.), and BtMV on sugar beet (Beta vulgaris L.). Aviruliferous GPAs were allowed to feed on source plants containing single infections of either BYV, BWYV, or BtMV for approximately $48 \mathrm{~h}$. After this time, leaf pieces containing approximately 10 aphids each were cut from source plants and deposited onto the basal leaves of sugar beet seedlings (approximately twoleaf stage) growing in $10-\mathrm{cm}$ (4-in) square pots containing greenhouse potting mix. Insect cages were placed over each plant individually to contain aphids and prevent movement between plants. Plants to be inoculated with a single virus received only 10 aphids that had fed on the source plant for that virus. Plants to be inoculated with two viruses received approximately 20 aphids (10 from each source plant). Similarly, plants inoculated with all three viruses received approximately 30 aphids. Mock-inoculated plants received approximately 10 aviruliferous aphids each. Previous studies in our laboratory have shown no difference in virus transmission efficiency or feeding injury to seedling beets when 10 to 50 aphids per plant were used for inoculation of viruses. Aphids were allowed to feed on healthy test plants for $48 \mathrm{~h}$, after which cages were removed and aphids eliminated by spraying with Orthene PT-1300 (Whitmire Micro-Gen Inc., St. Louis, MO). Each treatment (virus combination) consisted of at least five plants per beet breeding line. There were eight treatments including mockinoculation and four sugar beet breeding lines, for a total of at least 160 plants per experiment. Plants were assembled in a randomized pattern on the greenhouse bench. The entire experiment was repeated without alterations three times over a period of 18 months. Plants were maintained under standard greenhouse conditions for 8 weeks, under natural lighting, with greenhouse temperature fluctuations varying by season. Plants were watered once daily and provided with liquid fertilizer every 2 weeks with watering. The number of symptomatic plants per line per treatment was recorded weekly, and percent infection was calculated. Although all three viruses are common in California and are present in Monterey County where experiments were conducted, all plant material from tests was autoclaved prior to disposal as a matter of standard procedure.

Dot-blot hybridizations. Total nucleic acid samples were prepared from symptomatic leaves at 8 weeks postinoculation (wpi) using a modification of procedures described by Dellaporta et al. (10). To determine virus concentration, replicate dot blots were performed for each virus in single, double, and triple infections, using nucleic acid probes specific for detection of each virus. The BYV probe was a 602nucleotide portion of the coat protein gene of BYV (nucleotides 13638 to 14240) subcloned from a larger BYV clone kindly provided by V. Dolja (GenBank number NC001598). The probe used for detection of BWYV was the 563-nucleotide coat protein gene of another polerovirus, Beet chlorosis virus (BChV) (GenBank number AF167483). The BChV coat protein gene shares $98 \%$ sequence identity with the coat protein gene of our BWYV isolate (GenBank number AF473561). The probe efficiently detects both BChV and BWYV and was provided by H.-Y. Liu (20). The BtMV probe was derived from a clone developed in our laboratory, composed of a region encompassing the $3^{\prime}$ portion of the NIb coding region and the $5^{\prime}$ portion of the coat protein coding region. The clone was

Table 2. Susceptibility and tolerance of beet breeding lines to BYV, BWYV, and BtMV ${ }^{\mathrm{a}}$

\begin{tabular}{lccc}
\hline Line & BYV & BWYV & BtMV \\
\hline C37 & T & T & S \\
C76-39-5 & T & T & S \\
US75 & M & M & S \\
SP22-0 & S & S & S \\
\hline
\end{tabular}

a Abbreviations: BYV, Beet yellows virus BWYV, Beet western yellows virus; BtMV, Beet mosaic virus; $\mathrm{T}$, tolerance; $\mathrm{M}$, moderately susceptible; S, susceptible.

Table 1. Characteristics of yellows complex viruses

\begin{tabular}{|c|c|c|c|c|c|c|}
\hline Virus $^{\mathrm{a}}$ & Genus $^{b}$ & Vector(s) & $\begin{array}{l}\text { Mode of } \\
\text { transmission }\end{array}$ & $\begin{array}{l}\text { Virion } \\
\text { morphology }\end{array}$ & Tissues infected & Symptoms $^{\mathrm{c}}$ \\
\hline BYV & Closterovirus & $\begin{array}{l}\text { Myzus persicae } \\
\text { Aphis fabae }\end{array}$ & Semipersistent & Flexuous rods & Phloem & $\begin{array}{l}\text { Vein-clearing, } \\
\text { foliar yellowing }\end{array}$ \\
\hline $\begin{array}{l}\text { BWYV } \\
\text { BChV } \\
\text { BMYV }\end{array}$ & Polerovirus & M. persicae & Persistent & Icosahedral & Phloem & Foliar yellowing \\
\hline BtMV & Potyvirus & M. persicae & Nonpersistent & Flexuous rods & Systemic & Mosaic/mottle \\
\hline
\end{tabular}

${ }^{a} \mathrm{BYV}$, Beet yellows virus; $\mathrm{BWYV}$, Beet western yellows virus; $\mathrm{BChV}$, Beet chlorosis virus; $\mathrm{BMYV}$, Beet mild yellowing virus; $\mathrm{BtMV}$, Beet mosaic virus.

${ }^{\mathrm{b}}$ Closteroviruses $(1,2,12,15)$, poleroviruses $(8,22)$, potyviruses $(21,25)$.

c Virus symptoms on sugar beet (13). 
produced by reverse transcriptionpolymerase chain reaction (RT-PCR) amplification using BtMV-sequence-specific primers (Fwd: 5' CCAAACTCCTGAAGCACAT 3'; Rev: 5' CCTCTCCATCCATCATAACC $3^{\prime}$ ) and cloning of the 658nucleotide amplification product corresponding to nucleotides 8377 to 9034 of the BtMV genome (GenBank number AY206394) (25). Relative amounts of viral RNA were compared by phosphorimage analysis (Molecular Dynamics, Sunnyvale, CA) of dot blots, performed with stringent hybridization conditions. Plant ribosomal RNA concentrations were used as an internal standard to equilibrate total nucleic acid concentrations among samples. Ribosomal RNA concentrations were determined using a probe made from a ribosomal RNA clone provided by K. Perry (Cornell University, Ithaca, NY). Experimental data were considered in analysis only when all inoculated viruses uniformly infected plants, as confirmed by hybridizations. Data were log transformed to provide a more normal distribution for analysis. Cumulative log transformed data from three independent experiments were analyzed with one-way ANOVA adjusted by Tukey-Kramer HSD, using the program JMP 4.0 (SAS Institute, Cary, NC).

Fresh plant biomass. At the conclusion of each experiment ( $8 \mathrm{wpi}$ ), soil was gently brushed from roots, and plants were weighed to determine fresh plant biomass. Biomass data were log transformed to provide a more normal distribution for analysis. Log transformed data were analyzed with one-way ANOVAs adjusted by Tukey-Kramer HSD. A nested ANOVA by virus combination nested within sugar beet line also was performed on log transformed data. All statistical analyses were carried out with the program JMP 4.0 (SAS).

\section{RESULTS}

Plant reactions to mixed virus infections were similar among the four sugar beet lines tested (Fig. 1). Differences in plant biomass were observed between tolerant and susceptible lines, and reflected differences in the degree of tolerance to the yellowing viruses. Line SP22-0 was highly susceptible to all three viruses, as expected. Effects on plant biomass associated with mixed virus infection were most apparent in line SP22-0 $(P<0.0001)$, and only slightly less apparent in the moderately susceptible line, US75 $(P<0.026)$. There were no significant differences in plant biomass during mixed virus infections in the virus yellows tolerant lines C37 and C76-89-5. Interestingly, wholeplant biomass for the tolerant line $\mathrm{C} 37$ was highest across all virus combinations as analyzed by Tukey-Kramer HSD (data not shown). Significant differences were not observed between infections of individual viruses and mock-inoculated plants in

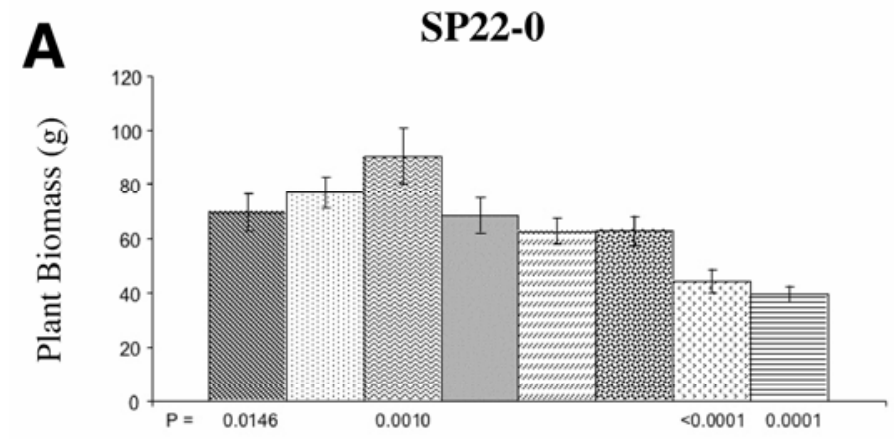

B

US75

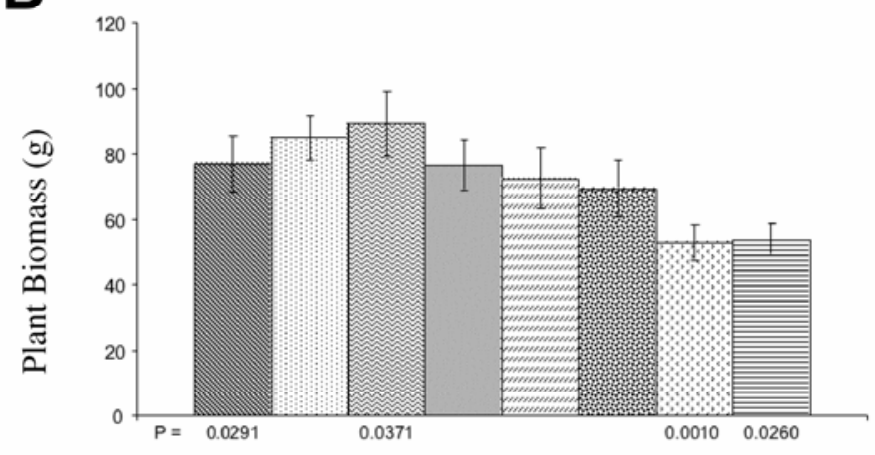

C

C37

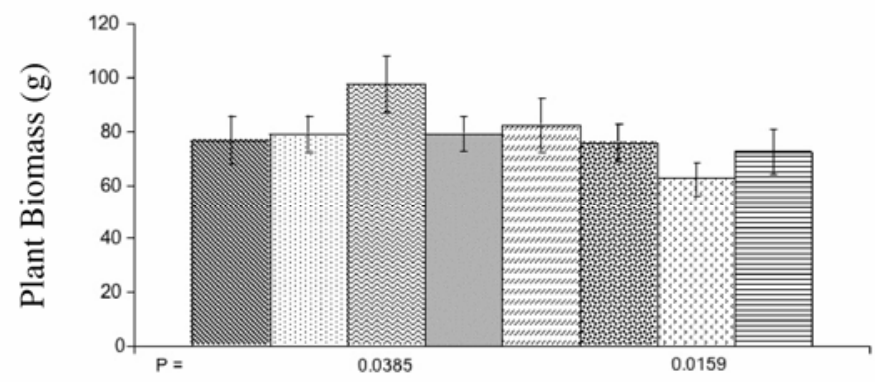

D C76-89-5

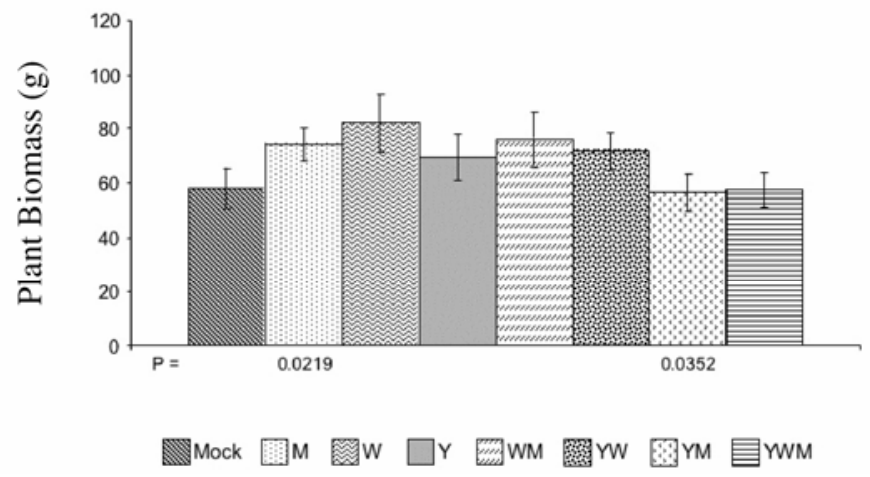

Fig. 1. Comparison of whole-plant fresh weight of sugar beet plants inoculated with single and mixed viruses among sugar beet lines exhibiting susceptibility and tolerance to yellowing viruses at 8 weeks postinoculation. Cumulative log transformed data from three independent experiments were analyzed by ANOVA for virus infection nested within sugar beet line. $P$ values are indicated below bars for significantly different treatments. A, SP22-0, line susceptible to Beet yellows virus (BYV) and Beet western yellows virus (BWYV); B, US75, line moderately susceptible to BYV and BWYV; C, C37, line tolerant to BYV and BWYV infection; D, C76-89-5, line tolerant to BYV and BWYV infection. Abbreviations of virus combinations in plants: Mock, healthy beet plants mock-inoculated by nonviruliferous Myzus persicae; M, Beet mosaic virus (BtMV); W, BWYV; Y, BYV; WM, co-infection of BWYV and BtMV; YW, co-infection of BYV and BWYV; YM, co-infection of BYV and BtMV; YWM, co-infection of BYV, BWYV, and BtMV. 
these studies, possibly because experiments were only maintained for 8 wpi. It was not feasible to continue the experiments past 8 weeks since pot size became a limiting factor, affecting beet growth and development.

Co-infection of BtMV with BYV resulted in a dramatic decrease in plant biomass. Susceptible lines SP22-0 and US75 co-infected with both BYV and BtMV demonstrated this effect most clearly $(P<0.0001$ and $P=0.0010$, respectively) when analyzed by TukeyKramer HSD, compared with single infections of either virus (Fig. 1). Co-infection by these viruses also resulted in lower plant biomass in the virus yellows-tolerant lines C37 and C76-89-5 $(P=0.0159$ and $P$ $=0.0352$, respectively) when plants were harvested at 8 wpi (Fig. 1). The tolerant lines allow virus accumulation but do not exhibit as much loss of biomass due to infection by the yellowing viruses (BYV and BWYV) as susceptible lines $(18,19)$. The yellows-tolerant sugar beet lines do not prevent BtMV infection or symptom expression. Plants of comparable sugar beet lines were not available with resistance or tolerance to BtMV. A source of BtMV resistance has been identified (17), but plants of this developmental line have an atypical growth habit, making direct comparisons with cultivated sugar beet difficult.

Visual observations of plants also indicated clear differences in growth within breeding lines between plants singly infected with BYV or BtMV, and plants infected by both BtMV and BYV (Fig. 2). By 8 wpi, plants infected with both BYV and BtMV were severely stunted, while plants singly infected with either BYV or BtMV were only mildly affected compared with mock-inoculated beets. This pattern was observed for both tolerant and susceptible breeding lines, but visible stunting due to mixed virus infection was milder in the lines with tolerance to yellowing viruses (Fig. 2). Other virus combinations did not significantly reduce plant biomass compared with infection by each virus individually (Fig. 1).

Interestingly, at 8 wpi when plants were harvested, plants with single infections of BWYV had greater biomass than mockinoculated plants in most lines (Fig. 1). It is not clear what effect BWYV infection might have on stimulating beet growth early in development. Previous studies have documented that BWYV infection early in beet development can lead to reductions in sugar yield of up to $30 \%$ at harvest (32), suggesting that any potential growth stimulation is lost over the course of the growing season.

Timing of symptom appearance can be affected by mixed infection. Coinfection with BtMV had a substantial impact on the time at which symptoms were first observed on plants for both BYV and BWYV. Interveinal yellowing symptoms resulting from BWYV infection developed earlier during co-infection with BtMV than in single BWYV infections, indicating that co-infection with BtMV facilitates earlier development of the yellowing symptom (Fig. 3A to C) (5 to 7 wpi, $P<0.0001)$. The only exception was at 4 wpi, when BWYV symptoms appeared in a few singly infected plants in two of three experiments, but had not yet been observed in plants inoculated with both viruses $(P=0.0097)$. No symptoms of BWYV infection were observed prior to 4 wpi. Timing of appearance of initial BWYV symptoms in single infections was gradual and usually did not peak (approximately $80 \%$ of plants have symptoms) until 7 wpi (Fig. 3C). In contrast, coinfection with BtMV led to more rapid appearance of BWYV symptoms, with $80 \%$ of the plants exhibiting symptoms by 5 wpi (Fig. 3C). Tolerant lines developed BWYV symptoms at a slightly slower rate than did susceptible lines in single infections (Fig. 3A) (week 4, $P=0.0284$; week $5, P=$ 0.2469 ); however, mixed infection with BtMV reduced these differences, resulting in similar rates of symptom appearance between tolerant and susceptible sugar beet lines (Fig. 3B) (week 5, $P=0.0027$ ).

BYV symptoms generally developed more quickly than those of BWYV $(P<$ $0.0001)$, with most symptoms appearing between 4 and 5 wpi (Fig. 3F). Coinfection with BtMV, however, resulted in a slight decrease in the rate of BYV symptom appearance compared with that for BYV alone, based on the results of three independent experiments. This was particularly evident at 4 wpi $(P<0.0001)$, when approximately $35 \%$ of plants inoculated with BYV alone had interveinal yellowing symptoms resulting from BYV infection. In contrast, only $5 \%$ of plants inoculated with both BYV and BtMV exhibited BYV symptoms (Fig. 3F). Interestingly, by $5 \mathrm{wpi}$, approximately the same numbers of plants from single and double inoculations were expressing symptoms. There was no difference in the rate of infection for BYV alone or with BtMV among susceptible and tolerant lines (Fig. $3 \mathrm{D}$ and $\mathrm{E})$.

BtMV infection rates were uniform among all treatments and all sugar beet lines (data not shown). Similarly, the rate of symptom development in mixed infections involving BYV and BWYV did not

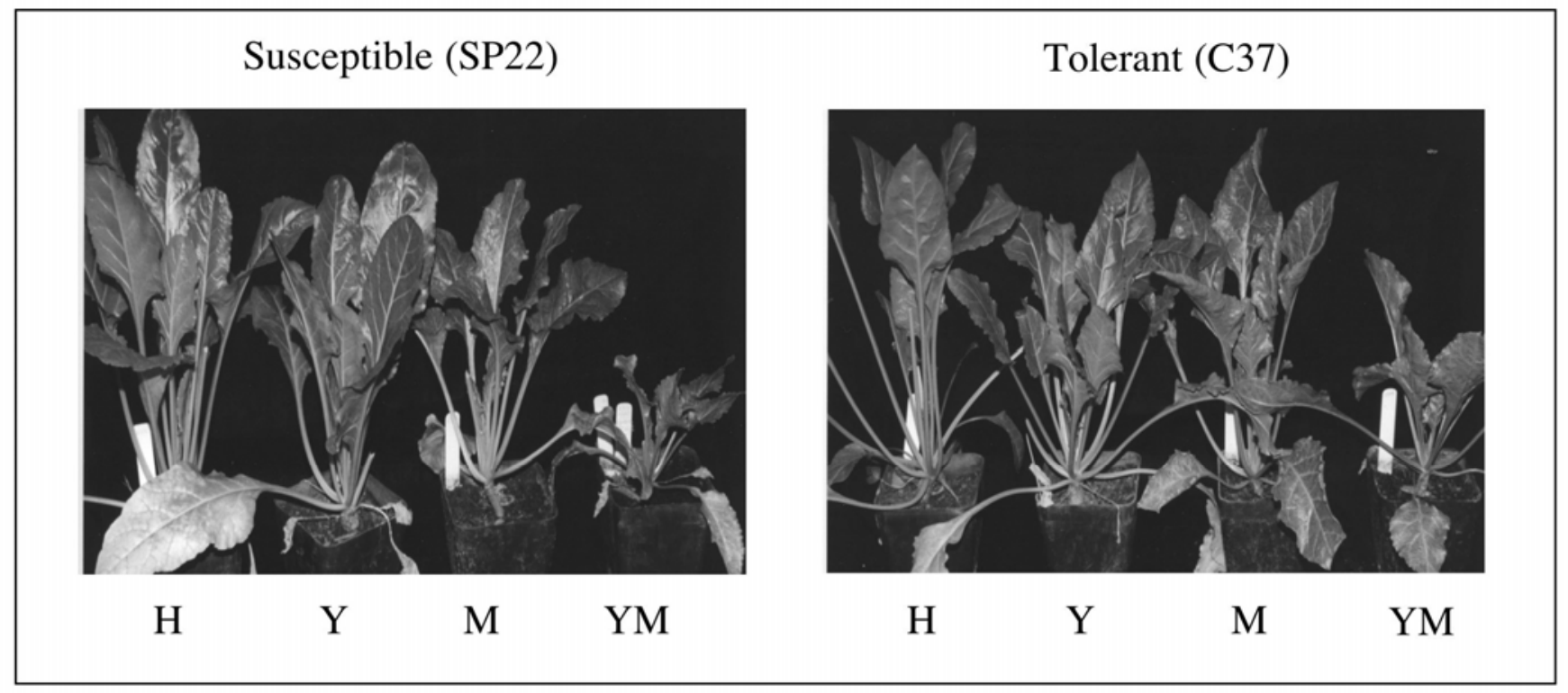

Fig. 2. Beet yellows virus (BYV)- and Beet western yellows virus (BWYV)-susceptible (SP22-0) and BYV- and BWYV-tolerant (C37) sugar beet plants at 8 weeks postinoculation. Plants were inoculated as follows: H, healthy beet plants mock-inoculated by nonviruliferous Myzus persicae; Y, infected by BYV only; M, infected by Beet mosaic virus (BtMV) only; YM, co-infected by BYV and BtMV. 
differ substantially from single infections (data not shown). Early BYV symptoms can be differentiated from those of BWYV by the appearance of yellow veins on infected leaves, since BWYV does not produce the yellow-vein pattern.

Virus RNA concentrations in sugar beet are also affected by mixed infec- tions. Prior to harvest of plants at 8 wpi, symptomatic leaves were collected to assay virus concentrations. Comparable leaves also were collected from mockinoculated and symptomless plants. Results of the sum of all sugar beet lines demonstrated that mixed infection by more than one virus led to increased titers of all viruses when compared with virus concentration in single infections (Fig. 4). Analysis of individual lines demonstrated the increase in virus concentration was not influenced by the degree of tolerance of the breeding line (data not shown). This is not surprising, since tolerance does not influence virus accumulation in plants, but
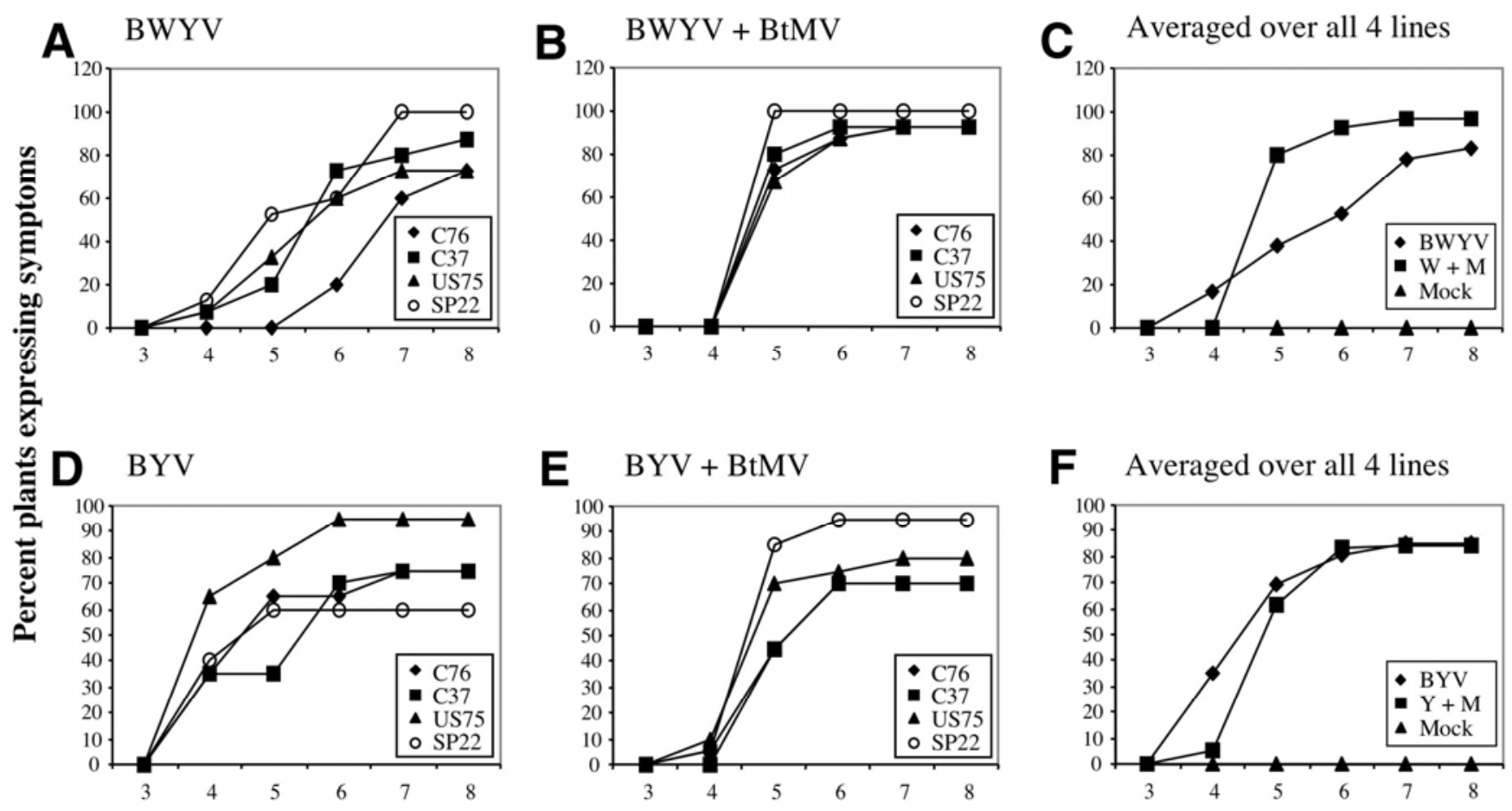

\section{Weeks post-inoculation}

Fig. 3. Time course of percent infection over time, comparing the effect of co-infection with Beet mosaic virus (BtMV) on initial development of yellowing symptoms induced by infection with Beet western yellows virus (BWYV) (A-C) or Beet yellows virus (BYV) (D-F). A-B, Mean percentage of plants expressing BWYV symptoms by sugar beet line in single (A) and mixed infection with BtMV (B). C, Mean percentage of plants expressing BWYV symptoms per week in single BWYV infections and co-infection with BtMV. D-E, Mean percentage of plants expressing BYV symptoms by sugar beet line in single (D) and mixed infection with BtMV (E). F, Mean percentage of plants expressing BYV symptoms per week in single BYV infections and co-infection with BtMV. Data presented are cumulative from three independent experiments.

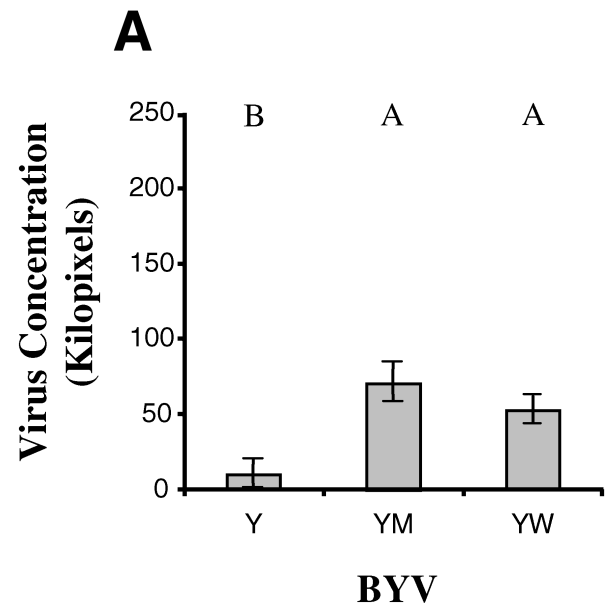

B

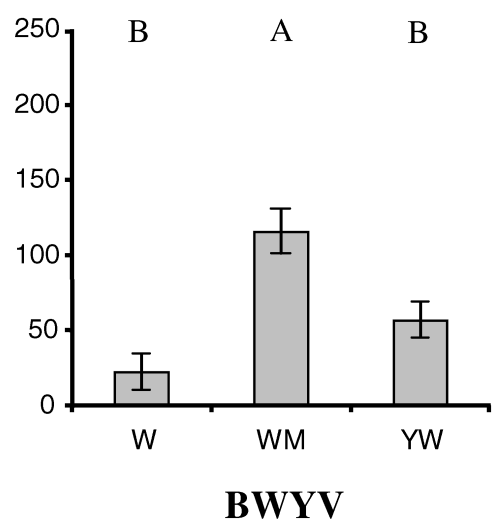

C

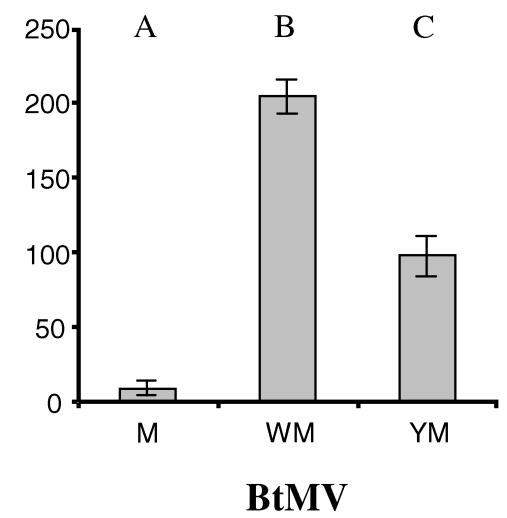

Fig. 4. Comparison of mean virus concentration in sugar beet leaves averaged over all plants in all sugar beet lines in single and mixed infections at 8 weeks postinoculation. Virus concentration is measured in kilopixels, based on the number of pixels in digitized imaging of dot-blot hybridizations with each probe after normalization of all hybridizations per plant with signal from a ribosomal RNA probe. Cumulative log transformed data from three independent experiments were analyzed with one-way ANOVA adjusted by Tukey-Kramer HSD. Letters above bars indicate significantly different treatments. A, Beet yellows virus (BYV) probe; B, Beet western yellows virus (BWYV) probe; C, Beet mosaic virus (BtMV) probe. Abbreviations of virus combinations in plants: Y, BYV; YM, co-infection of BYV and BtMV; YW, co-infection of BYV and BWYV; W, BWYV; WM, co-infection of BWYV and BtMV; M, BtMV. 
rather performance in the presence of virus infection. BYV titer (measured by relative concentration of BYV RNA) increased significantly during co-infection with both BWYV and BtMV compared with single infections, based on Tukey-Kramer HSD (Fig. 4A). BWYV titer also increased during co-infection with BtMV compared with single infections (measured by relative concentration of BWYV RNA) (Fig. 4B). BtMV titer (measured by relative concentration of BtMV RNA) increased dramatically in the presence of both BYV and BWYV (Fig. 4C).

\section{DISCUSSION}

In this study on the effect of co-infection by three different virus pairs, significantly increased stunting, as measured by decreased biomass, was observed in sugar beet plants co-infected with combinations of BYV and BtMV compared with single infections of either virus. Co-infection with these two viruses resulted in small plants with poor growth habit and lower biomass. In contrast, little additional stunting was observed during co-infection of sugar beet with BYV and BWYV, or with BWYV and BtMV, than with single infections. Plants co-infected with both BWYV and BtMV also developed BWYV-associated yellowing symptoms more quickly than plants singly infected with BWYV.

It may seem unusual that BtMV could influence infection by both BWYV and BYV, two fundamentally different viruses. Ample evidence is available, however, on synergistic interactions between potyviruses and viruses in other families (34). In most cases of synergism involving potyviruses, symptoms are more pronounced and the nonpotyvirus is usually the beneficiary of the synergism, accumulating to higher titers when the potyvirus is also actively replicating in the tissue. Potyvirus titer is usually affected very little by the nonpotyvirus, however (34). An exception to this was a study in which it was found that the BYV L-Pro can suppress infection and movement of Tobacco etch virus (TEV), a potyvirus, in Nicotiana tabacum. N. tabacum is a host of TEV, but not of BYV. This effect was clearly host specific, as it did not extend to $N$. benthamiana, a host of both TEV and BYV (11). No such inhibition of BtMV was identified in the studies presented here. Indeed, BtMV accumulation was stimulated by the presence of BYV (Fig. 4B), an effect also not found in most potyvirus synergisms. BtMV accumulation increased even more dramatically during co-infection with BWYV. As in most potyvirus synergisms, both partnerviruses, BYV and BWYV, increased in concentration during co-infection with the potyvirus, BtMV, compared with single infections of each virus alone. These results suggest that a unique relationship may exist between BtMV and phloemlimited viruses in general.
While BWYV and BYV are clearly very distant genetically and structurally, they exhibit a number of key similarities that support this hypothesis. Both BYV and BWYV are phloem-limited viruses $(15,22,23,28)$ that produce the same characteristic yellowing symptom on beet leaves as a result of interference with normal vascular transport and disruption of photosynthetic capabilities $(9,24,26)$. Both have similar effects on BtMV accumulation, and both accumulate to higher titers during co-infection with BtMV (Fig. 4). Based on this hypothesis, it might seem odd that significant stunting, as measured by decreased biomass, was only observed during co-infection of BYV and BtMV. One possible explanation as to why coinfection of BtMV with BWYV did not lead to significant stunting, in contrast with co-infection of BYV and BtMV, relates to differences in the nature of single infection by BYV and BWYV. First, infection by BYV alone has a much greater impact on sugar beet growth and sugar content than infection by BWYV $(5,6,13,32)$. Second, any decrease in plant biomass resulting from interactions between BWYV and BtMV may be masked by the stimulated growth associated with BWYV infection that was observed during the first few weeks after infection in these studies (Fig. 1).

This is not the first time a member of the Closteroviridae has been found to facilitate accumulation of a potyvirus. Karyeija et al. (16) demonstrated that titers of the potyvirus Sweet potato feathery mottle virus (SPFMV) were elevated 600fold as a result of co-infection by the phloem-limited crinivirus Sweet potato chlorotic stunt virus (SPCSV; family Closteroviridae). In that study, the authors suggested that SPCSV might enhance multiplication of SPFMV in non-phloemassociated tissues by interfering with phloem-dependent signaling that may be associated with host defenses. It is possible that a similar function might occur between BtMV and one or both of the two phloem-limited viruses associated with this study.

Interesting parallels also exist between the results presented here and previous studies on the effect of potyvirus infection on PLRV accumulation. While primarily phloem limited, PLRV, a polerovirus related to BWYV, can infect a limited number of parenchyma cells in $N$. clevelandii and $N$. benthamiana $(3,4)$. During coinfection with some potyviruses, however, PLRV accumulates to several fold higher concentrations in these hosts, and the number of PLRV-infected mesophyll cells is increased several fold $(3,4,29)$. The increase in virus accumulation in $N$. benthamiana was limited to phloem associated cells and was facilitated by the potyvirus helper component-protease (HC-Pro) facilitating virus accumulation in these tis- sues (29). In the studies presented herein, BWYV concentrations were also elevated several fold in the presence of BtMV. At the present time, it is not known how coinfection may impact the ability of BWYV to infect mesophyll cells, but future studies addressing this topic could indicate whether this type of synergism is common among poleroviruses in diverse hosts.

Co-infection with BtMV also decreased the time necessary for yellowing symptoms resulting from BWYV infection to appear in sugar beet leaves (Fig. 3A to C). It is possible that BWYV symptoms develop more rapidly simply because beet plants are already under stress from infection by BtMV. If so, similar results would be expected with mixed infections of BtMV and BYV; however, BYV symptom development was delayed slightly during co-infection with BtMV (Fig. 3D to F). Alternatively, the more rapid appearance of BWYV symptoms during co-infection of BtMV may result from physiological effects associated with increased accumulation of BWYV or possibly both BWYV and BtMV in the host vasculature during co-infection by these two viruses (Fig. 4B and $\mathrm{C})$. BWYV is restricted to phloemassociated cells, and it is thought that sieve tube blockage and degeneration of vascular tissue may be responsible for symptom development in infected plants (24). If so, it is possible that the higher levels of BWYV measured during mixed infection with BtMV reflected more rapid BWYV accumulation in the phloem, resulting in more rapid degradation of phloem function. BtMV also accumulates in nonphloem tissues, and it is possible that factors associated with phloem blockage and/or degradation may interfere with limited natural host defenses, or perhaps more likely other important physiological processes. This could explain the more rapid appearance of BWYV symptoms observed during co-infection with BtMV, possibly the decrease in plant biomass associated with co-infection of BYV and BtMV, and may be a general reaction resulting from interactions between potyviruses and certain phloem-limited viruses based on observations in other systems $(16,29,33)$.

Interactions between co-infecting viruses clearly play a substantial role in virus yellows infections of sugar beet, affecting symptom development, beet growth, and virus accumulation. The effects observed in this study, while performed under greenhouse conditions, were designed to examine interactions that can and do occur in nature between three unrelated viruses sharing a common vector and host. In most natural virus yellows outbreaks, the disease is caused by one or occasionally two viruses (based on diagnosis of samples sent to the USDA-ARS Virology Lab in Salinas for analysis). Clearly, BtMV has a significant impact on the severity of virus 
yellows in sugar beet, leading to increased stunting through interactions with BYV and more rapid appearance of BWYVinduced yellowing symptoms during coinfection with BWYV. Lines with tolerance to BYV and BWYV do not reduce virus accumulation. They do reduce the impact of both BYV and BWYV, as well as effects resulting from co-infection of these viruses with BtMV, including both time of appearance of initial symptoms (BWYV with BtMV) and stunting severity as measured by plant biomass (BYV with BtMV). Interestingly, there has been little concern in the sugar beet industry for BtMV even though the virus is worldwide in distribution and has been shown to decrease root yield by up to $20 \%(31,35)$. Losses related to co-infection with BtMV may have been attributed to BYV alone for many years. This new information supports earlier field studies that suggested a possible relationship between BtMV and increased severity of virus yellows (30), and calls attention to BtMV as a potential source of yield reduction during coinfection with BYV. Parallels were also observed between the effect of BtMV and two different phloem-limited viruses on sugar beet with respect to other unique potyvirus synergisms, warranting additional cytological and molecular studies on the effect of BtMV infection on phloem limitation and the molecular basis for increased virus accumulation during coinfection of sugar beet. These results support the hypothesis that a novel type of potyvirus-associated synergism occurs during co-infection with phloem-limited viruses $(29,33)$.

\section{ACKNOWLEDGMENTS}

I thank R. T. Lewellen for providing the sugar beet lines used in these studies as well as for helpful discussions, J. L. Sears for assistance with aphid transmissions, M. Parrish-Evans for virus concentration studies, and A. G. Anchieta for statistical analysis of the data. Additional thanks go to R. Hammond and J. Murphy for critical review of the manuscript. This work was supported in part by grants from the California Beet Growers Association Industry Research Committee and the Western Sugar Company-Grower Joint Research Committee.

\section{LITERATURE CITED}

1. Agranovsky, A. A., Koonin, E. V., Boyko, V. P., Maiss, E., Frotschl, R., Lunina, N. A., and Atabekov, J. G. 1994. Beet yellows closterovirus: Complete genome structure and identification of a leader papain-like thiol protease. Virology 198:311-324.

2. Bar-Joseph, M., and Murant, A. F. 1982. Clos- terovirus group. CMI/AAB Descriptions of Plant Viruses. No. 260

3. Barker, H. 1987. Invasion of non-phloem tissue in Nicotiana clevelandii by potato leafroll virus is enhanced in plants also infected with potato $\mathrm{Y}$ potyvirus. J. Gen. Virol. 68:1223-1227.

4. Barker, H. 1989. Specificity of the effect of sap-transmissible viruses in increasing the accumulation of luteoviruses in co-infected plants. Ann. Appl. Biol. 115:71-78.

5. Bennett, C. W. 1960. Sugar beet yellows disease in the United States. U.S. Dep. Agric. Tech. Bull. 1218:1-63.

6. Bennett, C. W., and McFarlane, J. S. 1957. The effect of sugar beet virus yellows disease on sugar beet seed production. Plant Dis. Rep. 43:1188-1190.

7. Bennett, C. W., Price, C., and McFarlane, J. S. 1957. Effects of virus yellows on sugar beet with a consideration of some of the factors involved in changes produced by the disease. J. Am. Soc. Sugar Beet Technol. 9:479-494.

8. D'Arcy, C. J., Domeier, L. L., and Mayo, M. M. 1999. Luteoviridae. In: Virus Taxonomy: Seventh Report of the International Committee on Taxonomy of Viruses. C. Fauquet, ed. Academic Press, San Diego, CA.

9. De Koeijer, K. J., and van der Wert, W. 1995. Effect of beet yellowing viruses on light interception and light use efficiency of the sugarbeet crop. Crop Prot. 14(4):291-297.

10. Dellaporta, S., Wood, J., and Hicks, J. B. 1983. A plant DNA minipreparation: Version II. Plant Mol. Biol. Rep. 1:19-21.

11. Dolja, V. V., Hong, J., Keller, K. E., Martin, R. R., and Peremyslov, V. V. 1997. Suppression of potyvirus infection by coexpressed closterovirus protein. Virology 234:243-252.

12. Dolja, V. V., Karasev, A. V., and Koonin, E. V. 1994. Molecular biology and evolution of closteroviruses: Sophisticated build-up of large RNA genomes. Annu. Rev. Phytopathol. 32:261-285.

13. Dunning, A., and Byford, W. 1982. Pests, diseases and disorders of sugar beet. Deleplanque and Cie, B. M. Press, Sartrouville, France.

14. Hauser, S., Stevens, M., Mougel, C., Smith, H. G., Fritsch, C., Herrbach, E., and Lemaire, O. 2000. Biological, serological, and molecular variability suggest three distinct polerovirus species infecting beet or rape. Phytopathology 90:460-466.

15. Karasev, A. V. 2000. Genetic diversity and evolution of closteroviruses. Annu. Rev. Phytopathol. 38:293-324.

16. Karyeija, R. F., Kreuze, J. F., Gibson, R. W., and Valkonen, J. P. T. 2000. Synergistic interactions of a potyvirus and a phloem-limited crinivirus in sweet potato plants. Virology 269(1):26-36.

17. Lewellen, R. T. 1973. Inheritance of beet mosaic virus resistance in sugar beet. Phytopathology 63:877-881.

18. Lewellen, R. T. 1998. Registration of C76-89-5 parental line of sugarbeet. Crop Sci. 38(3):905.

19. Lewellen, R. T., Whitney, E. D., and Skoyen, I. O. 1995. Registration of C37 sugarbeet parental line. Crop Sci. 25:375.

20. Liu, H.-Y., Wisler, G. C., Wintermantel, W. M., and Sears, J. L. 2001. Differentiation of poleroviruses in sugarbeet. J. Sugar Beet Res. 38(1):84.

21. Lopez-Moya, J. J., and Garcia, J. A. 1999. Potyviruses (Potyviridae). Pages 1369-1375 in: Encyclopedia of Virology, 2nd ed. Granoff and Webster, eds. Academic Press, San Diego, CA.

22. Mayo, M. A., and Ziegler-Graff, V. 1996. Molecular biology of luteoviruses. Adv. Virus Res. 46:413-460.

23. Medina, V., Peremyslov, V. V., Hagiwara, Y., and Dolja, V. V. 1999. Subcellular localization of the HSP70-homolog encoded by beet yellows closterovirus. Virology 260:173-181.

24. Miller, W. A. 1999. Luteovirus (Luteoviridae) Pages 901-908 in: Encyclopedia of Virology, 2nd ed. Granoff and Webster, eds. Academic Press, San Diego, CA.

25. Nemchinov, L. G., Hammond, J., Jordan, R., and Hammond, R. W. 2004. The complete sequence, genome organization, and specific detection of Beet mosaic virus. Arch. Virol. (online) DOI 10.1007/s00705-003-0278-3.

26. Rossing, W. A. H., van Oijen, M., van der Werf, W., Bastiaans, L., and Rabbinge, R. 1992. Modelling effects of foliar pests and pathogens on light interception, photosynthesis, growth rate and yield of field crops. Pages 161-180 in: Pests and Pathogens, Plant Responses to Foliar Attack, P. G. Ayers, ed. Bios Scientific Publishers, Oxford, UK.

27. Russell, G. E. 1971. Beet mosaic virus. CMI/AAB Descriptions of Plant Viruses. No. 53.

28. Sanger, M., Passmore, B., Falk, B. W., Bruening, G., Ding, B., and Lucas, W. J. 1994 Symptom severity of Beet western yellows virus strain ST9 is conferred by the ST9associated RNA and is not associated with virus release from the phloem. Virology 200:48 55 .

29. Savenkov, E. I., and Valkonen, J. P. T. 2001 Potyviral helper-component proteinase expressed in transgenic plants enhances titers of Potato leaf roll virus but does not alleviate its phloem limitation. Virology 283:285-293.

30. Shepherd, R. J., Hills, F. J., and Hall, D. H 1964. Losses caused by Beet mosaic virus in California grown sugar beets. J. Am. Soc. Sugar Beet Technol. 13(3):244-251.

31. Shepherd, R. J., and Till, B. B. 1965. Effect of strains of the Beet mosaic virus on the yield of sugar beets. Plant Dis. Rep. 49:961-963.

32. Smith, H. G., and Hallsworth, P. B. 1990. The effect of yellowing viruses on yield of sugar beet in field trials, 1985 and 1987. Ann. Appl. Biol. 116:503-511.

33. Taliansky, M., Mayo, M. A., and Barker, H 2003. Potato leafroll virus: A classic pathogen shows some new tricks. Mol. Plant Pathol. 4(2):81-89.

34. Vance, V. B. 1999. Synergism: Plant viruses. Pages 1694-1699 in: Encyclopedia of Virology, 2nd ed. Granoff and Webster, eds. Academic Press, San Diego, CA.

35. Watson, D. J., and Watson, M. A. 1953. Comparative physiological studies on the growth of field crops. III. The effect of infection with Beet yellows and Beet mosaic viruses on the growth and yield of the sugarbeet crop. Ann. Appl. Biol. 40:1-37. 